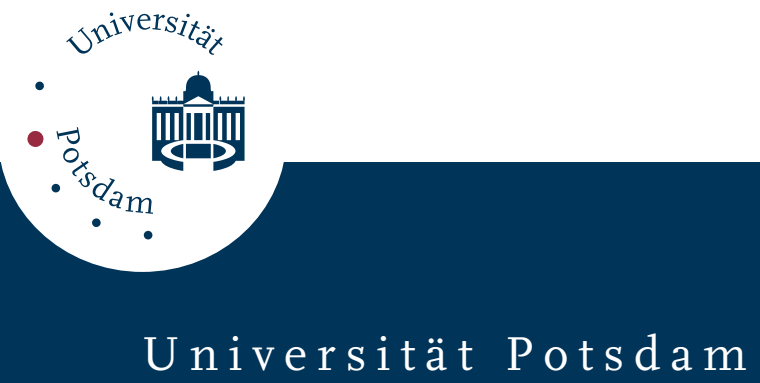

Margret Selting

\title{
Prosody in conversational questions
}

first published in:

Journal of pragmatics. - 17 (1992) 4, S. 315-345, ISSN 0378-2166

Postprint published at the Institutional Repository of the Potsdam University:

In: Postprints der Universität Potsdam

Philosophische Reihe ; 38

http://opus.kobv.de/ubp/volltexte/2010/3663/

http://nbn-resolving.de/urn:nbn:de:kobv:517-opus-36635

Postprints der Universität Potsdam

Philosophische Reihe ; 38 


\title{
Prosody in conversational questions*
}

\author{
Margret Selting**
}

My analysis of question-word questions in conversational question-answer sequences results in the decomposition of the conversational question into three systems of constitutive cues, which signal and contextualize the particular activity type in conversational interaction: (1) syntactic structure, (2) semantic relation to prior turn, and (3) prosody. These components are used and combined by interlocutors to distinguish between different activity types which (4) sequentially implicate different types of answers by the recipient in the next turn. Prosody is only one cooccurring cue, but in some cases it is the only distinctive one.

It is shown that prosody, and in particular intonation, cannot be determined or even systematically related to syntactic sentence structure type or other sentence-grammatical principles, as most former and current theories of intonation postulate. Instead, prosody is an independent, autonomous signalling system, which is used as a contextualization device for the constitution of interactively relevant activity types in conversation.

\section{Introduction}

The topic of my paper is prosody in question-answer sequences. My analysis is based on a corpus of question-answer sequences taken from informal conversations in German. I will primarily deal with the different linguistic structures of questions and their relevance for recipients. This analysis will show that a few common assumptions both in grammar and conversational analysis need to be revised.

I take a question to be the first part of an adjacency pair which makes the production of an answer by the recipient in next turn conditionally relevant (Sacks et al. 1974). A question defines restrictions for its answer. The answer

Correspondence to: M. Selting, FB 11: Sprach- und Literaturwissenschaften, Universität Oldenburg, Postfach 2503, D-W 2900 Oldenburg, Germany.

* A former German version of this paper with slightly different terminology and notation appeared in Marga Reis and Inger Rosengren, eds., Fragesätze und Fragen. Tübingen: Max Niemeyer Verlag, 1991.

** For many helpful comments of various sorts I am grateful to Peter Auer, Elizabeth CouperKuhlen, Dafydd Gibbon, Klaus Gloy, Elisabeth Gülich, Volker Hinnenkamp, Lucia Licher, the Executive Editor Richard W. Janney, and two anonymous referees of the Journal of Pragmatics. I would also like to thank Deirdre Graydon for checking my English for style and readability. A shorter version of this paper was read at the International Pragmatics Conference, Barcelona, July 9-13, 1990. 
should be coherent and should give the focused-on information; otherwise, the recipient of the question must account for the 'official' absence of the conditionally relevant activity.

Schegloff (1984) has convincingly argued that in the appropriate sequential position, any utterance might be interpreted as a question, regardless of its syntactic structure. Furthermore, utterances with syntactic interrogative structures can perform quite different conversational activities, not only, or even primarily, questioning. Schegloff argues that question-answer sequences might be just a special case of an adjacency pair. He therefore concludes that it is not fruitful to start an analysis by looking at questions.

I am arguing from a different perspective than Schegloff's. My starting point is a linguistic one, namely, clear cases of syntactic interrogatives, particularly those in which a question word such as the English wh-word type is used. These, however, can have further different syntactic, semantic and prosodic properties. I shall be looking at the way in which, within this category of clear-case syntactic questions, further linguistic resources are used to signal and constitute different types of conversational questioning. My claim is that such an analysis is insightful also for CA, because it shows that participants treat linguistic structures as constitutive signals.

My special interest is prosody, and especially intonation, in these questions. In grammar books and in much of linguistic research, the intonation of questions in most cases isolated or invented interrogative sentences - is commonly thought to be closely related to syntactic sentence structure types such as declarative, interrogative, imperative and exclamatory. The general assumption is that a particular syntactic sentence structure type in unmarked cases calls for a particular unmarked intonation; choices of other intonations are said to constitute marked cases. For instance, in German, declarative sentences are said to have falling terminal pitch; rising terminal pitch is said to turn them into questions. Interrogative sentences having a question-word like the English wh-word type ('W-Fragen') are commonly said to call for falling terminal pitch in unmarked ('neutral') cases, whereas rising terminal pitch in these interrogatives is claimed to be marked and interpreted as 'polite', 'interested', 'interpersonally marked', or the like. On the other hand, interrogative sentences having subject-verb inversion are often referred to as 'yes/no questions' ('Entscheidungsfragen'), and are said to reverse this picture by calling for rising terminal pitch in unmarked cases and falling terminal pitch in marked cases (Pheby 1981: 875; cf. also von Essen 1964, Klein 1980, 1982, Kohler 1977; for a description of a similar situation in English see Arndt and Janney 1987: ch. 6). Some recent generative models of sentence intonation in German (Wunderlich 1988), and recent experimental research on 'Satzmodus' in German (Altmann et al. 1989), are also based on this description.

Yet, Gumperz (1982: 112f.) has quite correctly pointed out that in sentences like John's , going versus John's, going, the distinction between statement and question is a pragmatic one. 
In my analysis, I will proceed from the interpretation of activity types in conversational interaction. In this paper, I want to demonstrate the following:

(i) I want to present evidence that - contrary to most previous and current thinking, at least about German and English (sentence) intonation prosody and intonation in interaction are not systematically related to grammatical sentence structure type, and do not primarily fulfil grammatical functions in conversational interaction. On the contrary, my analysis will demonstrate that prosody has to be conceived of as an autonomous signalling system which is used in conversation in co-occurrence with lexico-semantic and syntactic structures as a means of constituting and contextualizing particular interactively relevant activity types (Gumperz 1982).

(ii) Prosody needs to be analysed in co-occurrence with other properties of questions. I will show that the holistic category 'question' can be decomposed into three interpretively relevant components, which each contribute to the constitution of a particular type of conversational question that needs to be answered in a particular way. These three components are: (a) syntactic structure, (b) semantic relation to prior turn, (c) prosody. A question in which the speaker utilizes these components distinctively is systematically interpreted as making a particular answer by the recipient relevant in the next turn. The properties of this answer in the next turn can be looked upon as evidence for the interpretive relevance of the different question types. I will argue that - in addition to using lexico-semantic and syntactic features - speakers use intonation, i.e. the pitch contour of a prosodic unit, and other prosodic parameters, like loudness and variations in global pitch height, as independent constitutive components for the construction and contextualization of different types of conversational questioning.

The conception of prosody and intonation as an autonomous signalling system has been advocated by Bolinger since 1958, most recently in his 1986 and 1989 monographs (for a presentation and discussion of this line of reasoning about prosody as an autonomous system versus prosody as a grammatical system see Arndt and Janney 1987: ch. 6). It has been taken up by Gibbon (1984) and Knowles (1984), and more recently, it has been advocated by researchers in the generative paradigm who work on the relation between phonology and syntax, most notably Selkirk (1984) (for German cf. Uhmann 1988). These authors are primarily concerned with accent placement and its semantic interpretation in terms of 'focus'. Their work in this respect seems to be compatible with syntactic approaches to 'accent and focus' by Rochemont (1986), Jacobs (1988), Pasch (1990), Reis (1991), Rosengren (1991), and others. As far as I know, however, although they assign tonal elements to sentences, they say little more about the choice and functions of prosody and intonation than to claim that the choice of tonal elements of pitch accents for the expressive components of sentences is free (cf. Selkirk 1984: 265). In studies of interaction, the argument that prosody and intona- 
tion are independent of grammar is a prerequisite for the analysis of these as contextualization devices in the way Gumperz (1982) suggests.

My analysis of empirical question-word questions from real conversations will show that, in choosing intonation and other prosodic parameters, speakers are not oriented towards the syntactic sentence structure type in the way traditional studies suggest, but rather towards the activity type to be constituted in the conversation: the last pitch movement in conversational questions is used as an activity-type distinctive contextualization cue.

\section{A taxonomy of conversational questions}

For this study, question-answer sequences were classified according to the conversational activities performed with them. Classification and analysis of question-answer sequences resulted in a taxonomy of conversational questions. My presentation in this paper is restricted to those types which in English would be called 'wh-questions' and 'echo questions'. I call them 'question-word questions'; the German set of question words contains was, wer, wie, wo, wann, warum, etc. ${ }^{1}$ The taxonomy is shown in figure 1 .

In discussing figure 1, I begin with the activities performed with conversational question-word questions, keeping the syntactic sentence structure type restricted to question-word questions. These, however, can have various other syntactic properties, which will be mentioned in the appropriate places in the analysis. Onto the activity types performed with these questions, I have tried to map the other two independent signalling systems from which speakers choose their cues to constitute these activity types: namely, a set of cues that constitute the 'semantic relation or topical focus in relation to last turn' and 'prosody'. After briefly introducing the question-types in the upper section of the diagram in general, I will illustrate these activity types in section 3 of this paper by analysing data extracts. In my conclusions, I will come back to the autonomous systems listed in the bottom section of the diagram.

Most fundamentally, I differentiate between "unrestricted "open" conversational questions', and 'restricted conversational questions'. The difference between these two types of question results from their respective semantic relations to the prior turn: in unrestricted 'open' conversational questions, the speaker chooses, or presents a topical focus as, a new topical focus in relation to last turn, and thus tries to bring about a new topical orientation for further on-topic talk. In contrast to this, in restricted conversational questions, the speaker does not choose a new topical focus or bring about a new topical orientation, but, on the contrary, continues a prior topical focus and now

1 Question-word questions are used as a model here; the taxonomy of conversational questions reconstructed for this type is, to a large part, also valid for other types of conversational questions. 


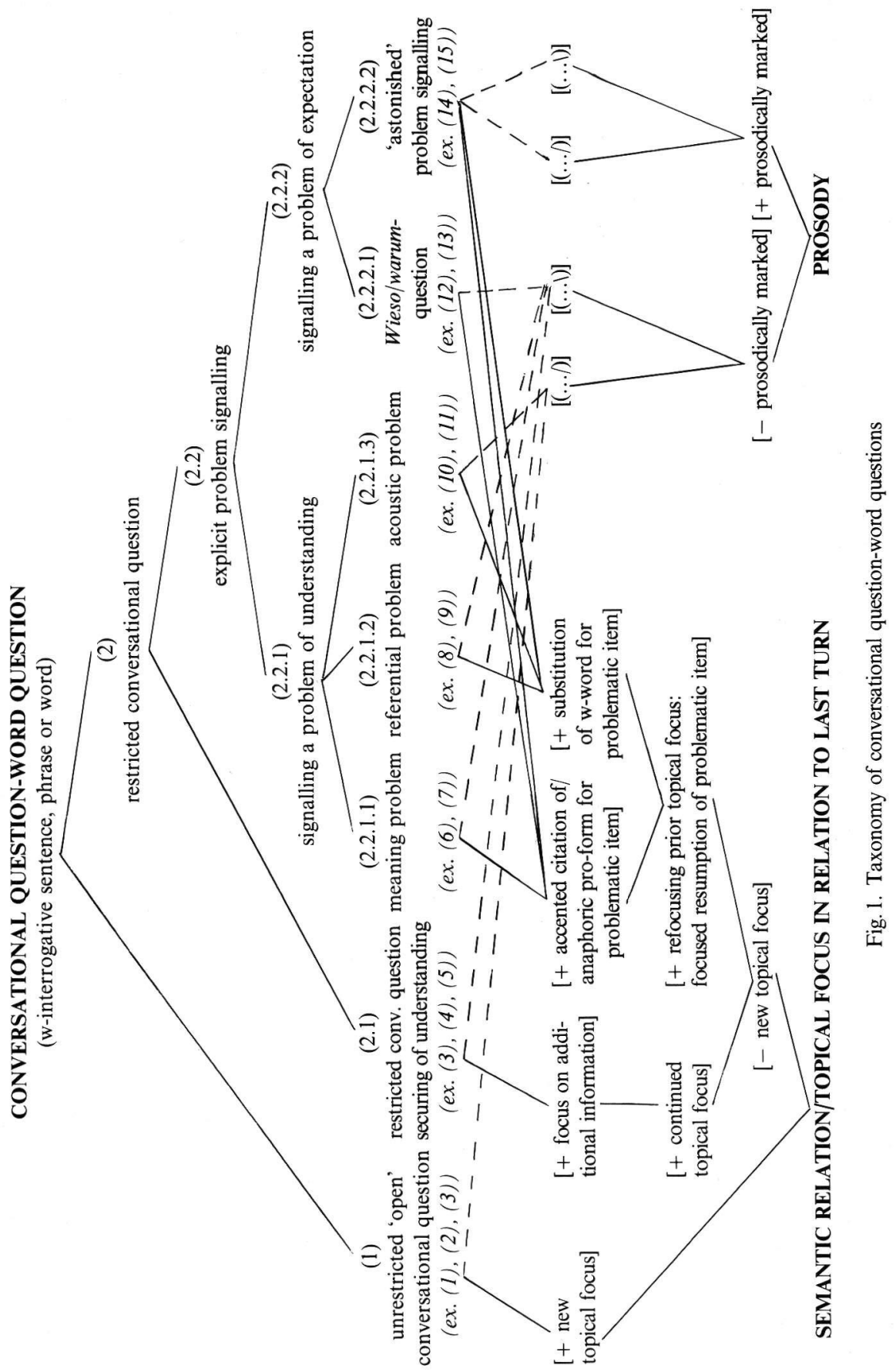


produces on-topic or continuous topical talk with respect to that prior topical focus (cf. Maynard 1980 for the terminology adopted here). Restricted conversational questions may either be detailing on-topic utterances; most often they are used to check or secure understanding of the prior turn. Or they explicitly signal a conversational problem by refocusing on a prior topical focus and suspending further topic-developmental talk.

In restricted conversational questions, the speaker asks for, and focuses on, additional information related to a previously established topical focus, in order to detail or to explicitly check his or her own understanding or inferences with respect to prior turns. In this sense, utterances that secure understanding are on-topic utterances with respect to a prior topical focus, thus fitting somewhere between the unproblematic continuation of conversational talk and explicit problem signalling. Such questions can possibly initiate side sequences (Jefferson 1972).

In problem signalling, however, a prior topical focus is refocused on, and further topical talk is suspended. The refocusing takes the form of an explicit, focused resumption of the problematical item from a prior turn. This way of dealing with a conversational problem takes the form of a repair sequence, more precisely, an other-initiated self-repair, in Schegloff et al.'s (1977) terms. Within this type of activity, the precise form of the resumption, and the prosodic structure of the question, differentiate between problem types. ${ }^{2}$

\section{Data extracts to illustrate and support the taxonomy}

In the following, I will present some data extracts which illustrate the taxonomy. ${ }^{3}$ The transcription conventions are given in Appendix B. The transcription is intended to represent the most important prosodic parameters of speech in conversation, particularly the intonation of utterances. ${ }^{4}$ For

2 In formulating the features which distinguish between question types in the taxonomy and in Appendix A, I do not follow strictly binary categorizations in terms of $[+\mathrm{x}]$ versus $[-\mathrm{x}]$. Categorizations such as these only seem justifiable for the features [ \pm new topical focus], [ \pm focused-on resumption of problematical item from last term] and [ \pm prosodically marked]. In most other cases, the distinction between a [ - feature] and a [ + feature] did not correspond to a difference in marked/unmarked with one of the set featuring as an unmarked and the other as a marked member. For instance, it would be a theoretical point with far-reaching theoretical implications to assign either falling or rising terminal pitch the status of $[+]$ and the other member of the set the status of $[-]$. To avoid this sort of assignment, I noted $[+x]$ and $[+y]$ in these cases. By redundancy rule, this only implies that if $[+x]$ then $[$ not $[+y]]$ and vice versa.

3 Within my own collection of question-answer sequences, the distribution of question-word questions is as follows: 46 unrestricted 'open' conversational questions, 42 restricted conversational questions detailing on a prior topical focus or securing of understanding, 16 meaning problems, 10 referential problems, 15 acoustic problems, and 17 problems of expectation.

4 For more detail on this system, which has a lot in common with Bolinger's (cf. esp. 1986) description, see Selting (1987d and 1988). 
purposes of the analysis presented in this paper, it is only necessary to look at the terminal pitch movements in the question-turns; these are notated in the transcript line for prosody beneath the text. The terminal pitch movement is either a rising or falling pitch movement on a prominent (i.e. accented) syllable and the following unaccented syllables, or it is a falling terminal pitch movement on an accented syllable plus a rising pitch movement on the following unaccented syllables. ${ }^{5}$ Features of prosodic marking will be explained when necessary in the analysis. I will deal primarily with the questions in the starred lines of the transcripts and their answers.

\subsection{Unrestricted 'open' conversational questions}

Extracts (1) and (2) show examples of unrestricted 'open' conversational questions:

(1) $\mathrm{K} 1: 513-522$

((After Nat has explained that she has been working a lot:))

1 Nat: und äh: ich war kaPUTT =

$\langle$ aspirated $\rangle$

$\langle\mathrm{p} \quad \mathrm{p}\rangle$

and eh: I was exhausted

2 Nat: [ = das: das GING überhaupt nich ne

3 Ida: $\left[\begin{array}{cccc}\langle\mathrm{p} & (\mathrm{l} & & /) \\ & & \mathrm{ja} & \mathrm{p}\rangle \\ & & 1 & \mathrm{hmm} \\ \text { it } & \text { it didn't work at all you know }\end{array}\right.$

4 Nat: ... hja ..

5 Ida: WIE lange GEHT das da .

* $\mathrm{H}(\mathrm{l} / \mathrm{l})$

how long does that go on

6 Nat: BIS um:äh: .. HALB zwölf ZWÖLF
$\mathrm{F}(1$
till eh
half twelve twelve
((i.e. 11.30 or midnight $)$ )

7 Ida: NAja ... ((drinks some coffee $))$
( 1 )
oh well

5 The other parts of the contour are relevant for e.g. the signalling of cohesive thematic relations and conversational styles. For instance, in question series, successive questions, depending on their contours, might contextualize different conversational activities and styles, and evoke associations and interpretive schemata like 'questioning s.o.', 'talking s.o. down', 'arguing', 'having an everyday chat', etc. (cf. Gumperz 1982, Tannen 1984, Selting 1988). 
8 Nat: $[$ WAS machs DU:

* $\quad \mathrm{H}(\mathrm{l} \quad \mathrm{l})$

9 Ida: what are you doing $\quad$ das GEHT ja noch..

10 Ida: ä ICH bin in som: .. äh BIStro: . restoRONG : =

$\mathbf{F}(/ \quad 1 \quad 1 \quad)$

e I am in like a eh bistro restaurant

((After this, Ida describes this bistro in detail.))

(2) K5: 285-291

1 Lea: also ich ich muß mich DE:R:maßn ÄRgern über die ne

$\mathrm{T}, \mathrm{F}(\mathrm{l}$

so I I am so much annoyed by her you know

2 Cis: un wieSO:

* $\quad \mathrm{M}(/)$

and why

3 Lea: .... weil DIE: äh . ((clears her throat))

$\mathrm{M}(1)$ -

because she eh

4 Lea: die MACHT innerhalb der: ähf

$\mathrm{M}(\mathrm{I}$

she makes within the eh

5 Lea: literaTURwissenschaftlerin in der FRAUNforschung

students of literature working on women's studies

6 Lea: [ ne DERmaßn MIEse: , poliTIK ne

7 Cis: $\begin{array}{rr}\text { such } a & \text { foul policy you know } \\ \mathrm{mhm}\end{array}$

((Lea continues to tell a particular incident.))

In the starred lines of these extracts, we find unrestricted 'open' conversational questions, all with terminal rising pitch. In (1) there are two finite question-word interrogative sentences; extract (2) gives an example of an elliptical question-word interrogative in an unrestricted 'open' conversational question. In all cases, the questions initiate a new topical focus, and thus bring about a new topical orientation for the further conversational development. In (1):5 the focus goes from the amount of work to the times of work; in (1):8 it goes from, so to speak, my job to your job. In (2), Lea states in line 1 that she is annoyed, and in line 2, Cis focuses on her reasons for this. In all these cases the recipient gives an answer to the question. In many cases, but certainly not all, answers to such questions are elaborate, and result in longer contributions. In (1): $5 \mathrm{ff}$., where Nat only answers briefly, the floor nevertheless seems to be returned to her, and she asks the next question in line 8 . The 
recipients seem to treat this question type as focusing, but not restricting, their reactions. This type of question seems to be a useful technique for producing topic-changing utterances or focusing on new topical foci without taking the floor for an extensive turn.

\subsection{Restricted conversational questions}

In the next extract (3), we first find an unrestricted 'open' question and then a question which continues the prior topical focus and calls for on-topic talk on that prior topical focus.

(3) K2: 12-17

1 Nat: was HAS du denn da für NARbm ...

$\mathbf{R}($ / where did you get those scars

2 Ida: ACH sod*. JA das: .. die SIEHT nur so: $\mathrm{H}(\backslash) \mathrm{M}(\mathrm{l})$ - $\mathrm{F}(\mathrm{I}$ oh well well that that only looks so

3 Ida: SCHRECKlich aus weil die nicht geNÄHT wordn is . bad because it wasn't stitched up

4 Nat: was HAS enn da geMACHT

M( $1 \quad 1 \quad)$ what did you do then

5 Ida: da hab ich mich mal geSCHNITTn inner SCHUle .. $\langle$ all $>\mathrm{F}(1 \quad 1 /)$ that was where I once cut myself at school

6 Ida: also quasi n SCHUL* UNfall sach ich da immer zu

$$
\text { L, F( } 1 \text { 1 } \quad \text { ) - }
$$

so sort of a school accident I always call it

((Ida laughs for about 2 seconds, after that she tells the story of this incident.))

In line 1, Nat asks an unrestricted 'open' question with rising terminal pitch. Note that here the last rising pitch movement is shifted into the very last unaccented syllable after the final falling pitch movement. ${ }^{6}$ The focus here is on Ida's scars, and possibly their origin. In her answer, though, Ida shifts focus to how these scars look.

In the second question in 4 , Nat focuses on the topical focus of the scars and their origin again. The question has falling terminal pitch. It seems to

- Shifts like these can be effectively used as stylistic devices. If the last pitch movement is shifted, this in itself and the pitch movements before the last one are free to participate in e.g. signalling stylistic and cohesive relations between units (cf. Selting 1988). 
focus the topic more narrowly than before, and to call for on-topic talk on that topical focus. This is indeed what happens in Ida's next turn. After her short answer in 5, Ida pauses, a point at which Nat could take the floor, and after this, in 6, Ida signals her willingness to relate the story. After laughing, she tells the story about her scars in detail in the next passage, thus possibly giving the more elaborate answer that Nat wanted to elicit with her first question.

Other examples of restricted conversational questions, explicitly securing understanding, are (4) and (5):

(4) K1: 99-109

((The topic is the over-representation of women in university seminars.))

1 Ida: also ICH fin das immer FÜRCHterlich wenn: . n da

$\begin{array}{llccc}\mathrm{F}(1 & 1 & ) & - \\ \langle\text { all } & \text { all〉 } & & \langle 1 & 1 \\ \text { well I think it's } & & \text { terrible } & \text { if: } & \text { there }\end{array}$

2 Ida: sone ÜBERbevölkerung von FRAUN besteht

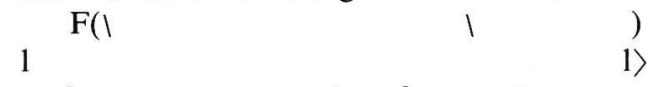

such an overrepresentation of women is

3 Nat: find ICH AUCH ....

$\left\langle\mathrm{p}\left(\begin{array}{lll}\mathrm{M}(/ & 1 & \\ \mathrm{p}\rangle\end{array}\right.\right.$

that's what I feel too

4 Ron: das is ja sowieSO: . grundSÄTZlich ne

$$
\mathbf{M}(1) \quad \mathbf{M}(1 \quad /)
$$

that's the case anyway always you know

5 Ida: J AA . aber in: . in VIEln veranstaltungn is das so

(1) F ( /

yea but in: in a lot of classes it is so

6 Ida: masSI:V da so .... ${ }^{*}$ mh

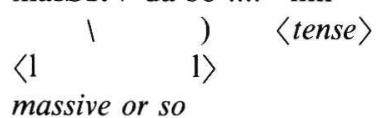

7 Nat: ((draws in breath)) wastuDIERS du denn .

* $\mathrm{H}(1)$ are

8 Nat: [ich mein das KOMMT ja auch immer

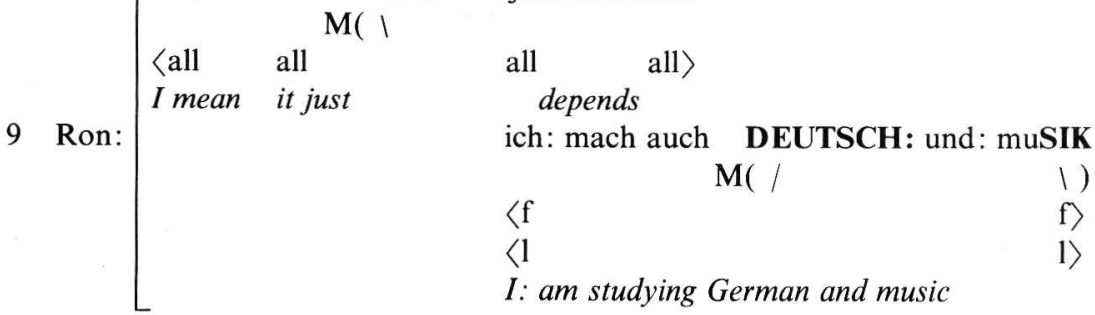




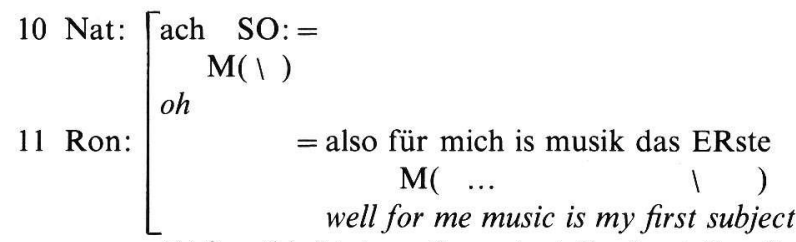

((After this Nat continues to talk about the situation in the German department.))

In (4), Ida and Nat, two female students, have declared that they do not approve of the over-representation of women in university seminars. Ron, a male student, reacts by pointing out that this is the normal situation. In line 7 , Nat obviously wants to make sure (question with falling terminal pitch) what subject Ron is studying, since the ratio of women students might vary with the subjects and, without more precise ratios having been mentioned, they might be talking about quite different situations after all (cf. also her continuation in line 8). In his answer, Ron mentions his subjects. Nat's reaction is the changeof-state signal (Heritage 1984) ach SO:, which signals that she has just now changed a former assumption. This reaction retrospectively confirms the interpretation of Nat's question in line 7 as a question seeking to secure understanding by checking an assumption.

(5) K1: 429-437

1 Ida: ich MACHdas hier zuENde ..

M( - $\quad$ all $>$
I am going to finish it here

2 Ida: un mal SEHN was DANN kommt

$\mathrm{F}(1$

and let's see what comes up then

3 Nat: in WELchem semester BIS du denn

$\mathrm{R}(1 \quad 1 \quad)$

which semester are you in then

4 Ida: . also im . in KUNST im DRITTN und im .

$\mathrm{R}($ /

well in in arts in the third and in

5 Ida: [ in DEUTSCH im VIERTN .

$\mathbf{F}(1$

in German in the fourth

6 Nat:

7 Ida: weil ich am anfang mal geWECHselt hab

$\langle$ all >

because at the beginning I changed (subjects) 
8 Ida: $\left[\begin{array}{l}\text { hin und her (?und?) } \\ \text { to and fro } \\ \\ \mathrm{hmm} \\ \mathrm{V}\end{array}\right.$

((After this, Ron resumes talk about the quality of universities and a possible change to another one.))

In (5), Ida has been telling the others that her university doesn't offer very good courses in her subject, but that nevertheless she intends to stay and finish her university education there. In line 3, Nat asks (question with falling terminal pitch) what semester Ida is in. It seems as if Nat hasn't reckoned on Ida's being at an age when she might start thinking about finishing her studies. This is also what she implies by the use of the particle denn. By asking the question, Nat initiates a side sequence focused on a hitherto inexplicit assumption underlying their interaction; by this means she is checking her understanding of Ida's reasons for talking about the decision to finish her university education at her present university. The new information that Ida now gives in lines 4-5 seemingly corresponds to Nat's expectations, who now only reacts with acknowledgement tokens. After Ida's answer, the suspended topic of conversation is resumed.

In contrast to the unrestricted 'open' questions, which have a new or seemingly new topical focus and rising terminal pitch, questions with falling terminal pitch continue talk on a prior topical focus, or focus on matters that have hitherto been inexplicitly assumed. They elicit additional information, often to check, or to clarify, the questioner's inferences and understanding of prior turns. In questions of this kind, we most often find the particles denn or, less often, eigentlich. In many cases, the accented syllables include the finite verb or the question-word; anaphoric elements referring back to the prior turn are not accented, and thus not focused on in this type of question. Recipients often, but by no means always, seem to take these questions as requests for shorter and more to-the-point, or on-topic answers; before elaborations into longer contributions, speakers often seem to leave room for possible recipient reactions or negotiations.

The analysis so far can be seen as a partial confirmation of an old stereotype: in the question-word questions looked at so far, rising terminal pitch does indeed seem to contextualize a question as an unrestricted 'open', and an in some sense 'real' question. This confirms the common sense assumption that questions have rising intonation. Yet, in my analysis, this is true only for a relatively discrete, precisely defined type of questioning activity in conversation, not for a syntactically defined sentence structure type. 


\subsection{Explicitly signalling problems}

Neither unrestricted 'open' questions nor restricted questions that explicitly secure understanding refocus directly on a problematical issue in the prior turn. This is exactly what distinguishes them from explicit problem-signalling questions. Problem-signalling questions initiate so-called 'other-initiated selfrepair'. Their common feature is that they have a focused-on resumption of a problematic item from the prior turn. The form of resumption of prior talk, and the prosodic structure of the question, distinguish between different problem types: problems of understanding vs. problems of expectation. ${ }^{7}$

Compared to Schegloff et al.'s (1977) approach, I change perspective here: instead of conceiving of repair (and the conversational system more generally) as a 'self-righting mechanism', I try to reconstruct the participants' perspectives and categorizations while they are doing repair. That is, I look more closely at how they signal and contextualize specific types of conversational problems during repair initiation, and how they treat particular - preferably corresponding - types of problems during the repair proper. This analysis shows that participants distinguish between different types of conversational problems, and deal with these differently. Furthermore, at least in some contexts, there is a preference structure or preference hierarchy among these different types of problems (cf. esp. Selting 1987a, b; cf. also 1987c).

\subsubsection{Signalling a problem of understanding}

Within the category of problems of understanding we can further distinguish between meaning problems, referential problems, and acoustic problems.

When signalling a meaning problem or, more precisely, a problem of semantic interpretation of an item from the last turn, the problematical item is refocused on by means of an accented citation or anaphoric pro-form, for instance, in questions like was ist $x$ ('what is $\mathrm{x}$ ')/was heißt das ('what does that mean'), with falling terminal pitch:

(6) K4: 268-273

1 Eli: un das ERste mal in einer SALzadisko $\mathrm{F}(/$ and the first time in a salsa disco

2 Lea: $[$ was is DAS den $n$

* $\quad\langle$ all $>\mathrm{F}(1 \quad)$

3 Cis: $\begin{gathered}\text { what is that } \\ \mathrm{mhm} \\ V\end{gathered}$

7 Most of the types of problems dealt with here may also be signalled by means other than question-word interrogatives or question-words. For a more detailed analysis of problem handling in everyday conversation see Selting (1987). 
4 Eli: dassis irgnwie ne ne be STIMMte art von $\mathrm{M}(\mathrm{I}$ that's like a a particular type of

5 Eli: [ TANZ öh ... den die da offensichtlich T ANzn

6 ?: $\quad$ dance eh which they seem to dance there $\mathrm{mhm}$

(7) $\mathrm{K} 4: 45-59$

1 Lea: dann KOMMS du aus der femiNIstischen $\mathrm{M}(\mathrm{I}$ then you come from feminist

2 Lea:[ theoloGIE oder was ... jetz von MÜNster ne ..
theology or what now from Münster don't you
3 Cis: $\mathrm{mmhm}$ nhn

4 Lea: $:$ weil da SITzen doch die (?????)rotfraun ne

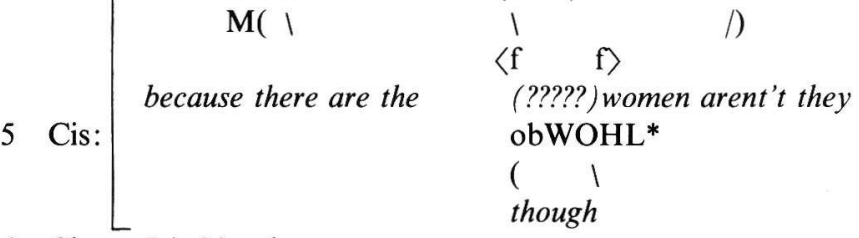

6 Cis: JA JA mhm

$\mathrm{F}(1 \quad 1) \quad / /$ yeayes uhum

7 Eli: [ was is denn femiNIstische* .. theoloGI E

8 Cis: $\left[\begin{array}{cc}\mathrm{F}(1 & \begin{array}{c}\text { । } \\ \text { but what is feminist } \\ \end{array} \\ & \text { theologIE }\end{array}\right.$

9 Lea: DAS muß man $\underline{\text { DIE }}$ fragn

$$
\begin{aligned}
& \mathrm{H}, \mathrm{F}\left(\begin{array}{ll}
/ & \mathrm{f}
\end{array}\right) \\
& \langle\mathrm{f} \\
& \text { that you must ask them }
\end{aligned}
$$

$((\ldots))$

14 Cis: $\mathrm{m}$ : ... also es is EIgndlich:

$$
\mathrm{M}(/ \quad)
$$

well basically it is

15 Cis: ja: .. ä so im zuSAMMnhang mit de w . äh: ne:

well eh a in connection with the eh a 
16 Cis: im zu SAMMnhang mit der FRAUNbewegung entstandene

$\mathrm{F}(/$

in connection with the feminist movement originated

17 Cis: ((pustet)) ... art theoloGIE zu treibn

((puffs)) way to do theology

In (6):2 the pro-form $D A S$ anaphorically refers back to $S A L z a d i s k o$ in line 1; in (7):7 the problematical item is cited. In both cases, the recipient explains the meaning of the problematical item; in (7) this only starts in 14, after an 'intermezzo' in which Lea jokingly states that only adherents of feminist theology could answer that question. The fact that the recipients respond with further explanations suggests that they infer that the source of trouble is a lack of knowledge.

In contrast to this, in the following types of problems, question-words like was ('what'), wo ('where'), wie ('how'), but not warum, weshalb, wieso ('why'), are substituted for the problematical item. Intonation is used to differentiate between the signalling of referential problems and acoustic problems.

In extracts (8) and (9), referential problems are signalled:

(8) K2: 253-264

1 Nat: oah ich glaub präsiDENT hat auch kein

$\mathrm{F}(\mathrm{I}$

oh I think president isn't

2 Nat: inTRESse daran ....

interested in

3 Nat: so muSI:K oder .. welche FÄcher

$\mathrm{M}[\quad(1) \quad(1)$

subjects like music or which subjects

4 Nat: pädaGOgik war das noch RUSsisch ..

education there was Russian

5 Nat: nee slaVIstik ÜBERhaupt glaubich ne ..

$\mathrm{F}(1 \quad 1 \quad /)$

no Slavonic studies in general I think you know

6 Nat: [so AUFrechtzuerHALten

7 Ron: $\begin{gathered}\text { in keeping them up } \\ \text { na das IS ja dasSELbe ne } \\ \mathrm{F}(1 \\ \text { but that's the same isn't it }\end{gathered}$

8 Nat: :... J A

$\mathrm{H}(/)$

is it

9 Ron: HMhm .. DENke SCHON ne ....

$\mathrm{L}(1$ /) $\mathrm{M}(/$ I $/$ /


10 Ida: WAS sla VIstik un RUSsisch

* 11 Nat: $\left[\begin{array}{cc}\mathrm{L}(1) \mathrm{F}(1 \text { I }) \\ \text { what Slavonic studies and Russian studies } \\ \text { sla VIstik un R USsisch } \\ \mathrm{F}(1 \text { I } \\ \text { Slavonic studies and Russian studies }\end{array}\right.$

12 Nat: ... DOCH . S TIMMT

$$
\begin{array}{ccc}
\mathrm{L}(- & \mathrm{L}(1 \\
\text { sure } & \text { right }
\end{array}
$$

(9) $\mathrm{K} 1: 245-250$

1 Nat: has DU denn schon mal solche sachen geMACHT ...

$$
\mathrm{H}, \mathrm{S}(\text { / }
$$

have you ever done such things

2 Ron: WAS für SAchen

* M, F( I I )

which things

3 Nat: so . FRAUNsachen oder so .. speZIELL .....

$\mathrm{H}, \mathrm{S}(/ \quad) \quad \mathrm{M}(/ \quad)$

such women's stuff or so particularly

4 Ron: hm: .. ach SO ichMUßte grade als: .
(1) $\mathrm{M}(\mathrm{I}$
oh I had to just when

5 Ron: du so erZÄHLT has an .. ((draws in air audibly))

you were telling

6 Ron: ähn pädaGOgikseminar n denken wo ich MITgemacht hab $\mathrm{M}(\mathrm{I}$ eh think of a seminar in education which I participated in

In (8), the referential problem is signalled in line 10. The question-word $W A S$ ('what') is substituted for the referring expression das in line 7. The question that signals the problem - WAS - has falling pitch. In this case, the questioner Ida immediately adds a candidate problem treatment herself, which is confirmed by Nat's parallel problem treatment in line 11: she substitutes a different referring expression for the problematical one. In (9):2, the questionword WAS für ('which') is substituted for the problematical referring expression solche in line 1; the trouble source is further specified by the repetition of the head of the noun phrase sachen. Here, too, the problem is solved by finally substituting a new referring expression FRAUN as the first element in the compound FRAUNsachen for the old problematic one. Thus, when the old problematical referring expression is only substituted by a new referring expression, the recipient seems to infer that the source of trouble is not a real lack of knowledge (requiring more information), but only a problem of reference, or a momentary gap in recall. No further information is necessary. ${ }^{8}$ 8 A few of the examples given in Schegloff et al. (1977) seem to be of this problem type: e.g. (1977: 369, fn. 15): 
Acoustic problems are also signalled by a substitution of a question-word for the problematical item or stretch of talk. This time, however, the pitch rises:

(10) BB12/1B: 42-47

1 Soc: dann müssen se inne SENnestadt gehn .

( 1 )

then you must go to the Sennestadt ((= name of a suburb))

2 Soc: äh dort zum dort wo sie sich auch ANgemeldet habm

eh there to there where you registered too

3 Kli: ja die KINdergeld s geKOMM

$\mathrm{F}(1 \quad 1 \quad)$

yes the child allowance has arrived

A: I have a:-cousin teaches there.

D: Where.

A: Uh:, Columbia.

Cf. also the following from Sacks et al. (1974: 702):

Fern: Well they're not comin',

Lana: Who.

Fern: Uh Pam, unless they c'n find somebody.

In the following extract from Schegloff et al. (1977: 379) (Part of (69)), the wh-word with falling intonation is followed by a candidate repair or problem treatment with rising intonation, which is rejected in next turn.

Jim: Some imagination.

Roger: Who:se.mi:ne?

Jim: No hi:s.

See also Scheḡoff (1987: 207) for more examples.

Auer (1984) gives examples in which reference is a problem, but in which the referential problems are predominantly signalled in the form of meaning problems. Accordingly, in most of the examples, the problematical item or name is not just treated by substituting another referring expression for the first one, but by giving an explanation and further information about the person in question. The difference between these problem types seems to result from the different assumptions associated with them: when signalling referential problems in the form 'w-word with falling pitch', the assumption seems to be that the problem signaller only has a momentary recall or interpretation problem, whereas the form for the meaning problem seems to indicate that the problem signaller has a real lack of knowledge which has to be dealt with (cf. Selting 1987 for more detail).

In the following extract, too, the question incorporates a repetition of the problematical item from last turn, which could indicate that James didn't expect Michael being Mike and expected more information about this Michael (ex. (49) from Schegloff et al. 1977: 371):

Vic: First of a:::1l, uh Michael, came by:,

I tell you-

Vic: Tch!

James: [Who's Michael.

Vic: [Picture the story.

Mike: $\overline{\mathrm{M} / / \mathrm{e}}$.

Vic: Michael came by. Michael ... 
4 Soc: was

$(/)$

what

5 Kli: ds KINdergeld is geK OMM

$\mathrm{F}(\mathrm{I}$

$$
\langle\text { all }\rangle
$$

6 Soc: ja

the child allowance has arrived

(11) BB3/6B: 6-12

1 Soc: ich KANN ANrufn

$\mathrm{F}(1) \quad$ I
I can telephone

2 Soc: wenn sie das möchtn

( ... )

if you want that

3 Soc: weil das is D RÜbm in dem geBÄUDE der ravensberger spinneR EI

$\langle$ all > $\mathrm{M}(1$

because that is over there in the building of the ((name))

4 Soc: wenn sies beSCHREIbm könn is das ja kein probLEM

$\mathrm{M}($

if you can describe it it is no problem

5 Kli: we(nn) ich WAS

* $\quad \mathrm{M}(\ldots, \quad /)$

$\langle$ all all $\rangle$

if $I$ what

6 Soc: wenn sie s beSCHREIbm kön n

$\begin{array}{llll}\langle 1 & 1 & 1\end{array}$

if you can describe it

7 Kli: JAA. JAA KANN ich

$\begin{array}{lcc}\text { ( I ) } & \mathrm{F}(1 \quad 1 \\ \text { yes } & \text { yes I can }\end{array}$

In both cases above, was ('what'), with rising pitch, substitutes for the problematical item or stretch of talk. In (10) this is the entire prior turn; in (11) it is the stretch located by the repetition of the pre-problematical items wenn sie in the deictically shifted form we(nn) ich. In both cases, the recipients respond by repeating the problematical items. By providing a simple repetition of the problematical item, recipients seem to categorize and treat mere channel disturbances, or the like, as the source of trouble, not recall problems or lack of knowledge. ${ }^{9}$

9 A large number of examples given by Schegloff et al. (1977) illustrating other-initiated selfrepair display this problem type. See the examples (25)-(27), in which the repair initiation is $H u: h$ ? or What? with rising intonation, and examples (28)-(36), in which the initiations Who?, Where?, $W$-when?, or these words plus a preceding item to locate the problematic item, are used: All the 
3.3.2. Signalling a problem of expectation

Problems of expectation with respect to the last turn can be signalled either by questions with the question-word wieso ('why'), or by a so-called 'astonished' version of other question types.

Extract (12) gives an example of a question with the question word wieso; these questions always have falling pitch.

(12) K5: 102-116

1 Eli: ich F INde diese URlaubsregelung an der UNI $\mathrm{F}(1$

I think these holiday regulations at the university

2 Eli: VÖLlich UNsinnich ne .

$1 \quad 1 \quad /)$

are absolutely foolish you know

3 Eli: ich $\mathbf{H A B}$ nichts von meinem urlaub ne..

$\mathrm{F}(\uparrow \uparrow$

/)

I don't get anything out of it you know

4 Lea: $[$ ICH AU nich

$\mathrm{M}(/ \quad 1 \quad)$

same with me

5 Eli: $\quad$ man ARbeitet ja sowieSO ne

$\mathrm{R}(/ \quad \uparrow \backslash /)$

you go on working anyway you know

6 Lea: J A

( 1 )

yeah

7 Cis: - WIEso GIBTS da ne offizielle URlaubsregelung

* $\quad \mathbf{M}\left(\begin{array}{l}\text { * } \\ \text { * }\end{array}\right.$

8 Eli: why is there an official holiday regulation

9 Eli: G IBT eine urlaubsregelung

$\mathrm{F}(\mathrm{I}$

is a holiday regulation

10 Eli: aber es IST Eben NICHT SO .

but it isn't just such

ja es

yes there

11 Eli: wie in jedm: SCHULbetrieb

like in every school organization

what?, The who?, Met whom?, To a where?. All these 'questions' have rising intonation, which is transcribed as '?'; in one case the question is transcribed as Where, to indicate a rising intonation to mid level only. They all yield a repeat, or very near repeat, of the prior turn, or the repeat of precisely the located part of it. They thus have a different intonation and are treated differently than the examples quoted in the preceding footnote as examples for referential problems given in the literature. 
12 Eli: oder an jedm ANderem betrie b .

( $\uparrow$ -

or in every other organization

13 Eli: wo du WIRKlich mal fü:r FÜNF wochn im jahr $\mathrm{F}($ /

where you really for five weeks a year

14 Eli: alles stehn und LIEgn lassen KANNS T

you can leave anything and everything

15 Eli: [und WIRKlich URlaub machn kannst ne =

$\mathrm{F}($ / $\uparrow$ /)

and you can really be on holiday you know

16 Cis:

17 Lea:

$=\mathrm{mhm}$

$=\mathrm{mhm}$

Eli states in lines 1-3 that she doesn't approve of the holiday regulations at the university, because she doesn't get anything out of her holidays. In line 7, Cis signals her problem. The question word wieso ('why'), with falling pitch, is used in a separate unit, and in the following unit the problematical item URlaubsregelung is cited from line 1 . In the problem treatment answer, the holiday regulations at the university are contrasted with those in other institutions.

The wieso-question in extract (13) is formulated as a finite interrogative sentence:

13 K1: 993-1004

1 Nat: aber wieso FÄHRS du denn dann wenn: .

* H(l ) -

but why then do you drive if

2 Nat: KANNS du nich mal $\mathrm{n}$ wochenende HIERbleibm (0.8) $\mathrm{H}, \mathrm{F}(\mathrm{I}$

can't you stay for a week end sometimes

3 Nat: [ich mein wenn du

〈all I mean if you $^{-}$all〉

4 Ron: JAA = ich hab . ähm: . FEste beZIEhungn da ne =

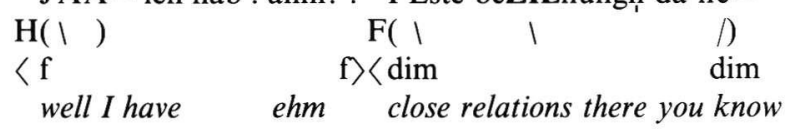

Ron has been complaining that instead of driving home every weekend, he sometimes would prefer to stay in his place near the university. Nat, assuming that a student is free to decide, has not expected this, and signals this problem via the wieso-question. Ron answers by giving some background information about his private life. 
In the extracts (14) and (15), prosodically marked 'astonished' questions are used to signal problems of expectation.

(14) K5: 210-221

1 Eli: HAS du denn an deiner diss ge ARbeitet in letzter zeit $\mathrm{M}, \mathrm{R}($ /

so have you been working on your dissertation recently

2 Lea: NEE NUR als ich wußte dann is der doktoRANdntermin ..

\section{( 1 ) R( /}

no only when I knew there was a meeting for postgraduates

3 Lea: hab ich mich mal KURZ $\mathrm{n}$ abend H INgesez

$$
\mathrm{M}(1
$$

I sat down briefly for an evening

4 Lea: ((laughs for ca. 3 secs))

5 Lea: [J A un dannhab ich erst $n$ SPÖkes gemacht ne ((laughs))

$\mathrm{L}, \mathrm{R}(\mathrm{I}$

$\langle$ all $>$

well and then I first did some silly things you know

6 Eli: $\quad \begin{gathered}\mathrm{mhm} . . \\ 1 /\end{gathered}$

7 Eli: $[\mathrm{m}$ geNAU ja

8 Lea: $\begin{aligned} & m \text { exactly yes } \\ & ((\text { laughs }))\end{aligned}$

9 Cis: WAS has du gemach $\mathrm{t}$
* $\mathrm{H}, \mathrm{R}\left(\frac{T}{\Gamma}\right)$
$\langle\mathrm{f}\rangle$
what did you do

10 Lea: irgendwie so ZETtelchen geSCHRIEbm

$\mathrm{F}(\mathrm{I}$

I wrote some kind of note

11 Eli: sie hat ne ganz nette EINladung geschriebm

she wrote quite a nice invitation

12 Lea: ((laughs for ca. 2 secs))

13 Cis: ... hmhm

14 Eli: mit BILDchen und ziTAT

$\mathrm{F}(\mathrm{I}$

with pictures and quotation

Lea tells the others that she hasn't been working on her dissertation much recently, and on one occasion, instead of sitting down to work on it, she first did some silly things (see line 5). The problem signalling question in line 9, $W A S$ has du gemacht, is a focused-on resumption of the problematical expression $n$ SPÖkes gemacht from line 5, which was formulated there as a funny and self-ironical statement. The accent on the question word $W A S$ is stronger 
and louder than the surrounding accents. The whole turn is spoken with a high and rising global pitch. These two features, louder accent and higher pitch than in the surrounding stretches of talk, mark this question prosodically. Cis obviously uses prosodic marking as a resource to signal 'surprise' or 'astonishment'. ${ }^{10}$ As a result, it is not the signalling of an acoustic problem, and it is also more than just the signalling of a meaning problem with respect to the lexical item spökes. Cis, rather, is amazed by Lea's description of how she put off working on her dissertation; at least she perhaps hasn't expected a disrespectful characterization such as $n$ spökes machen, and is curious to know what activity this actually refers to.

Lea and Eli both answer this question by giving background information about the activity Lea has referred to with the expression $n$ SPÖkes gemacht. In answering, Lea doesn't take this problem seriously. She sticks to the selfironical modality initiated earlier, and answers that she wrote some kind of note, before she bursts into laughter again. Eli, however, also sticks to her own modality, and answers Cis' question seriously, telling her the real activity which Lea engaged in.

Thus, neither Lea nor Eli treat the signalled problem as an acoustic one, or as just an ordinary meaning problem. They both take it to be a problem of expectation with respect to the activities that Lea calls $n$ spökes machen, which she performs to put off working on her dissertation.

Another example of a prosodically marked signalling of a problem of expectation is (15):

(15) BB9/2B: 6-13

1 Soc: das KOstet allerDINGS

it costs though

2 Soc: sag ich Ihn ma gleich vorher

〈all all〉

I'll tell you beforehand

3 Soc: PRO seite drei MARK

$\mathrm{F}(1$

per page three marks

4 Klil: $\underline{\text { WAS }}$

$\mathrm{H}(\overline{T)}$

$\langle\mathrm{f}$ f $\rangle$

what

5 Soc: ich MUSS also jetz
I must then now

6 Soc: JEde beglaubichte SEIte nehm ich ihṇ drei MARK $\mathrm{F}(1$ every notarized page I charge you three marks

10 Cf. Selting (1991) for a systematic analysis of prosodic marking of this kind as a resource to signal 'astonished' questions. 
7 Kli2: . wieSO kostet das denn GE:L:D:

R(1 1 )

but why does it cost money

8 Kli2: der B RAUCHT das doch für ne . beWERbung
$\mathrm{R}(\mathrm{I}$
he needs
that
for an
application

Here, the problem-signalling question word $W A S$ is produced with a stronger accent than the surrounding accents, and in a high and rising pitch; again, these prosodic parameters contextualize 'astonishment'. In this case, however, Soc seems to avoid treating the problem of expectation. After she begins to refer to a set price in line 5, she restarts with a simple repetition of the already stated price, treating the problem as a simple acoustic problem - which she prefers to treating it as a problem of expectation, as signalled by Kli1. In 7, however, Kli2 signals the problem a second time, in a more explicit wiesoquestion and, in line 8 , she makes the expectation with which Soc's demand is incompatible explicit. This insistence confirms the interpretation of the prosodically marked question-word as the first signalling of a problem of expectation. Only later does Soc give the background information necessary to solve Kli1 and Kli2's problem of expectations.

The prosodic marking of such 'astonished questions' distinguishes them from corresponding unmarked versions. Their general interpretation seems to be 'astonishment' or 'surprise', and they are used to signal problems of expectation. ${ }^{11}$

In the signalling and treatment of problems of expectation, interlocutors generally seem to infer a contradiction between their own and the interlocutor's expectations. Appropriate problem treatment activities contribute to the clarification of the contradiction, in most cases by providing background information.

I thus claim that in the types of repair exemplified here, the form of repair initiation, and the repair proper, signal the interlocutors' categorization of the trouble source or, in my terminology, of the type of problem that they are

11 Especially the earlier transcripts in CA did not notate changes in global pitch. Therefore, it is not possible to identify prosodically marked turns in those transcripts. Yet, in some cases it might be possible that something like prosodic marking is involved in some extracts. Judging from the transcripts, for instance, the following example from Schegloff et al. (1977: 377, example 63) might possibly involve a prosodically marked signalling of a problem of expectation, with possibly a markedly strong accent in the question word:

A: It's just about three o'clock, so she's probably free. I'll call her now

B: What time is it?

A: Three, isn't it?

B: I thought it was earlier.

After his possibly prosodically marked question, B explicates the other expectation underlying his problem signalling. 
dealing with. These are characterized by particular assumptions that distinguish between the problem types. Thus, if dealt with in conditionally relevant ways, ${ }^{12}$ (1) acoustic problems are treated as if they were the result of mere channel disturbances, (2) referential problems are treated as if they originated only in momentary recall or in interpretation lapses, (3) meaning problems are treated as if they were problems resulting from a lack of knowledge, and (4) problems of expectation are treated as if they resulted from incompatible expectations. As can be easily seen, these problem-type distinctive assumptions are quite different in that they affect the assumed reciprocity basis of interaction in increasingly serious ways.

My analyses suggest that a reconstruction of participants' perspectives while doing repairs might yield yet further interesting internal structures within repair types. A close look at the repair initiations and repairs proper chosen by participants reveals the participants' categorization and handling of the problem in terms of an everyday, members', typology of problem types. The signalling cues themselves are of course only a resource: their use might not say anything about the real source of trouble, or about more severe underlying problems that might first be treated as less severe problems, but later turn out to be much broader misunderstandings. Schegloff's (1987) examples give evidence that in many cases, members first try to treat severe misunderstandings as if they were simpler problems, to see if this suffices for problem solving. ${ }^{13}$

12 For evidence that the relation between the problem signalling and the problem treatment in the repair types exemplified here is indeed one of conditional relevance, see Selting (1987a) and (1987b).

13 For more examples and analyses that clearly show the relationship of conditional relevance between particular forms of problem signalling and successive problem treatments by recipients, see Selting (1987a, 1987b) and Rost (1989: ch. 4.4.8ff.). My (1987a) study was based on a specific type of interaction: interaction between officials and clients in public administration offices. In many of those cases, however, the problem is not treated in the way conditionally relevant for the signalled problem type. Yet, if signalled problem types are not treated by the recipient in the conditionally relevant way but are 'recategorized', and treated as if they are different problem types, this recategorization shows a remarkably uniform direction: problems signalled as less preferred problem types tend to be recategorized and treated as more preferred problems. These kinds of recategorizations are oriented towards, and treated as, 'special cases' that need more than the usual interactive work: either the problem signaller ratifies the recategorisations, or $s /$ he insists on the treatment of the signalled problem by signalling it a second time. (Cf. extract (15) above for an example.) The change-of-state tokens ach so, ach etc. ('oh') (Heritage 1984) seem to be used as just such problem signaller's cues to accept and ratify problem treater's recategorization of a problem.

The uniform direction of recategorizations of problem types in the interaction between clients and officials seems to be largely due to a preference hierarchy among the problem types: in both problem signalling and problem treatment, there is evidence that acoustic problems are preferred to referential problems, and these again are preferred to meaning problems, and these again are preferred to problems of expectation. In the data I gathered from everyday conversation, the same problem types can be identified, but there is less evidence for a similar preference hierarchy in this context. 
In summary, a linguistically informed analysis that looks closely at the linguistic structures of conversational activities as contextualization devices might refine the sequential analysis. In the cases discussed here, syntactic, lexico-semantic, and prosodic devices and relations are used as activity-type distinctive contextualization cues within similar sequential environments. ${ }^{14}$

\section{Conclusions}

The components of conversational questions used so far can be grouped together to yield constitutive systems from which speakers choose cues to construct particular question types. The first, i.e., syntactic sentence structure type, was kept constant in this analysis. The other two, semantic relation and prosody, which are related to the distinctive forms of questions, correspond to the two autonomous systems given in the taxonomy in figure 1. The interpretation and treatment of these by recipients as particular question types, which call for particular types of expected answers in the next turn, is evidence of the interpretive relevance of these question types. Insofar as a particular question's routine interpretation and treatment in the next turn confirms and warrants the relevance of my taxonomy as a members' taxonomy, the type of answer can be listed as a fourth constitutive system. These four components can be represented as follows:

(1) Syntactic structure type of the question, which was restricted to:

$[+$ question-word interrogative sentence, or question-word phrase, or question-word];

(2) Semantic relation to prior turn: here it is relevant to distinguish between new and continued topical focus, and refocusing on a prior topical focus; and in the latter case between different forms of refocusing on a problematical item from the last turn.

[ \pm new topical focus]

[ \pm continued topical focus]

$[ \pm$ refocused topical focus: resumption of problematical item from last turn by anaphoric pro-form or substitution of question word for problematical item];

(3) Prosody of the question: falling versus rising terminal pitch movements, and prosodically unmarked versus prosodically marked questions. For some activities it is the prosody only which is distinctive and constitutive.

[ + pitch: falling versus rising terminal pitch movement]

[ \pm prosodic marking]

14 By a methodology similar to the one adopted here, Kelly and Local (1989) analyse understanding checks and signallings of meaning and hearing problems in the speech of localized Tynesiders talking with an interviewer. They also find that the interviewees, in word repetitions of an item presented to them, distinguish between different activities by prosody. 
(4) The particular structure of the question constituted by the choice of features from the above categories sequentially implicates a particular type of answer by the recipient.

[ \pm invitation to elaborate on the topic]

[ \pm expectation of more restricted and to-the-point answer]

[ \pm initiation of a side sequence].

Each type of question can now be represented as a cluster of constitutive features, which are used as contextualizing cues for this particular question type. This representation is given in Appendix A.

In conclusion, my analysis shows that questions as conversational objects can be decomposed into their constitutive interpretive components and signalling cues. Different types of questions can be distinguished that sequentially implicate different types of answers. This analysis shows that it can be quite useful to look closely at prosody and other linguistic features as signalling cues. Prosody is only one constitutive component, but it distinguishes importantly between different types of conversational questions that contextualize quite different conversational activities.

In my analysis, the syntactic sentence structure type has more or less been kept restricted to those question types which in grammar books are called question-word and echo-questions. Nevertheless, within similar or even identical syntactic and lexico-semantic structures, prosody, and especially intonation, was shown to vary and to have not sentence structure type, but activitytype, distinctive forms and functions in conversational interaction. Therefore, intonation cannot be systematically related to syntactic sentence structures or other sentence-grammatical principles. Neither can intuitive unanalysed global factors like varying 'politeness', 'interest', 'interpersonal markedness', or the like, account for the differences found in actual data.

My analysis in this paper, and my other analytical work on prosody in conversation, suggest that we have to keep apart accent placement, or the choice and placement of prominence, on the one hand, and the choice of local pitch movements in, and after, accented syllables, on the other. In order for the choice and placement of prominent accented syllables to achieve the intended (semantic) focus interpretation, speakers must take into account, and rely on, grammatical principles as resources, as particular recent studies on accent and focus suggest (cf. Selkirk 1984 and the literature referred to in section 1). In this area of 'accent and focus', a consensus view has emerged in which accent placement is viewed as a means of achieving the expression and interpretation of semantic focus (cf. also Bolinger's formulation of this issue (1982: 635)). But prosody, and above all intonation, is yet another parameter which cannot be explained with reference to syntactic sentence structure type, or to other grammatical principles, but which has to be analysed with reference to the organization of conversational interaction. Prosody and intonation are used as an autonomous signalling system, from which speakers 
choose activity-type distinctive contextualization cues for the constitution of interactively relevant activity types in conversation. The terminal pitch movements in conversational questions distinguish between conversational question types; and the other parameters of the intonation contour also seem to have more to do with style and rhetoric (Knowles 1984, Selting 1988) than with grammar.

\section{Appendix A: Types of conversational question-word questions and their clusters of constitutive features ${ }^{15}$}

Conversational question-word questions in general

[+ turn-exit and turn-yielding for focused-on reaction]

(1) unrestricted 'open' conversational question

[+ new topical focus]

$[+$ rising terminal intonation $(\ldots /)]$

[- prosodically marked]

[+ invitation to possible elaboration on the topic]

(2) restricted conversational question

[+ continued topical focus]

[ + expectation of a more restricted on-topic answer]

(2.1) restricted question detailing a prior topic and/or securing of understanding of prior talk

[ + continued topical focus with focus on additional information]

[- focused-on resumption of problematic item from prior turn]

[+ falling terminal intonation $(\ldots 1)]$

[- prosodically marked]

(2.2) explicit problem signalling

[+ focused-on resumption of problematic item from prior turn]

[ + expectation of a restricted answer]

[+ initiation of side-sequence]

(2.2.1) signalling a problem of understanding

[ - prosodically marked]

(2.2.1.1) meaning problem

[+ question word, except the wieso, weshalb, warum type]

[ + accented citation/anaphoric resumption of problematic item]

[+ falling terminal intonation $(\ldots 1)]$

15 For my use of the $+/-$ formalism cf. my footnote 2 . In this list, the features given for superordinate question types also apply for their respective subordinate question types. Subordinate question types are increasingly more specified by additional or more refined features. This list is not entirely free of redundancies. 


\section{(2.2.1.2) referential problem}

[+ substitution of question-word for problematic item]

[+ falling terminal intonation (... $)]$

(2.2.1.3) acoustic problem

[+ substitution of question-word for problematic item]

$[+$ rising terminal intonation $(. . / /)]$

\section{(2.2.2) signalling a problem of expectation}

[ \pm prosodically marked]

[ + accented citation/anaphoric resumption of problematic item/matter]

(2.2.2.1) Wieso/weshalb/warum-question

[- prosodically marked]

[+ falling terminal intonation (... $)]$

(2.2.2.2) 'astonished' problem signalling

[+ prosodically marked]

$[+$ terminal intonation falling $(\ldots /)$ or rising $(\ldots /)$ according to intended similarity to other question types]

\section{Appendix B: Transcription symbols}

Transcription symbols in the text line of transcripts:

aber DA kam aber DA kam

SIcher

si:cher

s:i:ch:er:

.

(0.8)

((laugh))

(? er kommt ?)

a(l)so

*

$\mathrm{n}, \mathrm{m}$

$\overline{\left[\begin{array}{c}\text { ich gehe } \\ \text { jaha }\end{array}\right.}$ primary accented syllable of a unit

secondary accented syllable of a unit

extra strong/loud accent

lengthening of a sound

lengthening of an entire word

brief pause of up to ca 0.5 secs.

each dot ca 0.5 secs. pause, here ca $1 \mathrm{sec}$

pause timed in tenths of a second

para- and/or non-linguistic events

transcriber dubious

doubtful sound within a word

glottal stop

syllabic sounds, according to sonority and length

latching

simultaneous talk, overlapping utterances

Transcription symbols in the prosody line(s) of transcripts:

Global pitch direction: (noted before the left '(' parenthesis)

$\mathrm{F}, \mathrm{R}, \mathrm{H}, \mathrm{M}, \mathrm{L}(\quad)$ notation of the global pitch direction before the accent sequence delimited by parentheses:

$\mathrm{F}=$ falling, $\mathrm{R}=$ rising, $\mathrm{H}=$ high, $\mathrm{M}=$ mid, $\mathrm{L}=$ low (Parentheses are usually notated before the first accent and at the end of the cohesive unit.) 
$\mathrm{H}, \mathrm{F}(\mathrm{r})$

combination of global characterizations

combined contours with only weak or no boundaries between units with different global pitch directions (e.g. 'paratones')

Accent (proto)types or unaccented local pitch movements in and after accented and/or unaccented syllables:

$\begin{array}{ll}1 & \text { falling } \\ - & \text { rising } \\ y & \text { level } \\ \Lambda & \text { falling-rising } \\ & \text { rising-falling }\end{array}$

Accent modifications:

$\uparrow \uparrow, \downarrow /, \uparrow-$

locally greater pitch movements than in surrounding accents, higher or lower accent peaks than usual sequence of unaccented syllables

(Outside the parentheses, local pitch movements function as 'pre-head' ('Vorlauf') or unstressed pitch movements independent of the accent sequence.)

Other prosodic parameters which are used with local or global extension, the extension is indicated by the position of the \langle\rangle :

$\langle f\rangle \quad$ forte, loud

$\langle 1\rangle \quad$ lento, slow

$\langle\mathrm{p}\rangle \quad$ piano, low

$\langle$ all $\rangle$ allegro, fast

$\langle$ dim diminuendo, decreasing loudness

\section{References}

Altmann, Hans, ed., 1988. Intonationsforschungen. Tübingen: Niemeyer.

Altmann, Hans, Anton Batliner and Wilhelm Oppenrieder, eds., 1989. Zur Intonation von Modus und Fokus im Deutschen. Tübingen: Niemeyer.

Arndt, Horst and Richard W. Janney, 1987. InterGrammar. Berlin: Mouton de Gruyter.

Auer, Peter, 1984. Referential problems in conversation. Journal of Pragmatics 8: 627-648.

Auer, Peter, 1986. Kontextualisierung. Studium Linguistik 19: 22-47.

Bolinger, Dwight, 1958. A theory of pitch accent in English. Word 14: 109-149.

Bolinger, Dwight, 1986. Intonation and its parts. Stanford, CA: Stanford University Press.

Bolinger, Dwight, 1989. Intonation and its uses. London: Edward Arnold.

von Essen, Otto, 1964: Grundzüge der hochdeutschen Satzintonation. Ratingen: Henn.

Gibbon, Dafydd, 1984. Intonation as an adaptive process. In: Dafydd Gibbon and Helmut Richter, eds., 1984, 165-192.

Gibbon, Dafydd and Helmut Richter, eds., 1984. Intonation, accent and rhythm: Studies in discourse phonology. Berlin: de Gruyter.

Gumperz, John, 1982. Discourse strategies. Cambridge: Cambridge University Press.

Heritage, John, 1984. A change-of-state token and aspects of its sequential placement. In: J. Maxwell Atkinson and John Heritage, eds., Structures of social action, 299-345. Cambridge University Press. 
Jacobs, Joachim, 1988. Fokus-Hintergrund-Gliederung und Grammatik. In: Hans Altmann, ed., 1988, 89-134.

Jefferson, Gail, 1972. Side sequences. In: David N. Sudnow, ed., Studies in social interaction, 294-338. New York: Free Press.

Kelly, John and John Local, 1989. Doing phonology. Manchester: Manchester University Press.

Klein, Wolfgang, 1980. Der Stand der Forschung zur deutschen Satzintonation. Linguistische Berichte 68: 3-33.

Klein, Wolfgang, 1982. Einige Bemerkungen zur Frageintonation. Deutsche Sprache 4: 289310.

Knowles, Gerald, 1984. Variable strategies in intonation. In: Dafydd Gibbon and Helmut Richter, eds., 1984, 226-242.

Kohler, Klaus J., 1977. Einführung in die Phonetik des Deutschen. Berlin: Erich Schmidt Verlag.

Maynard, Douglas W., 1980. Placement of topic changes in conversation. Semiotica 30(3/4): 263290.

Pasch, Renate, 1990. Überlegungen zu den Regeln der Interpretation von w-Interrogativsätzen. Manuscript. Berlin: Akademie der Wissenschaften (to appear in: Deutsche Sprache).

Pheby, John, 1981. Intonation. In: Grundzüge einer deutschen Grammatik. Von einem Autorenkollektiv unter der Leitung von K. E. Heidolph, W. Flämig und W. Motsch, 839-897. Berlin: Akademie-Verlag.

Reis, Marga, 1991. Echo-w-Sätze und Echo-w-Fragen. In: Marga Reis and Inger Rosengren, eds., 1991, 49-76.

Reis, Marga and Inger Rosengren, eds., 1991. Fragesätze und Fragen. Tübingen: Niemeyer.

Rochemont, Michael S., 1986. Focus in generative grammar. Amsterdam: Benjamins.

Rosengren, Inger, 1991. Zur Fokus-Hintergrund-Gliederung im Deklarativsatz und im w-Interrogativsatz. In: Marga Reis and Inger Rosengren, eds., 1991, 175-200.

Rost, Martina, 1989. Sprechstrategien in 'freien Konversationen'. Tübingen: Narr.

Sacks, Harvey, Emanuel A. Schegloff and Gail Jefferson, 1974. A simplest systematics for the organisation of turn-taking for conversation. Language 50: 696-735.

Schegloff, Emanuel A., 1984. On some questions and ambiguities in conversation. In: J. Maxwell Atkinson and John Heritage, eds., Structures of social action. Studies in conversation analysis, 28-52. Cambridge: Cambridge University Press.

Schegloff, Emanuel A., 1987. Some sources of misunderstanding in talk-in-interaction. Linguistics 25: 201-218.

Schegloff, Emanuel A., Gail Jefferson and Harvey Sacks, 1977. The preference for self-correction in the organisation of repair in conversation. Language 53: 361-382.

Selkirk, Elisabeth O., 1984. Phonology and syntax: The relation between sound and structure. Cambridge, MA: MIT Press.

Selting, Margret, 1987a. Verständigungsprobleme. Eine empirische Analyse am Beispiel der Bürger-Verwaltungs-Kommunikation. Tübingen: Niemeyer.

Selting, Margret, 1987b. Reparaturen und lokale Verstehensprobleme - oder: Zur Binnenstruktur von Reparatursequenzen. Linguistische Berichte 108: 128-149.

Selting, Margret, 1987c. Fremdkorrekturen als Manifestationsformen von Verständigungsproblemen. Zeitschrift für Sprachwissenschaft 6(1): 37-58.

Selting, Margret, 1987d. Descriptive categories for the auditive analysis of intonation in conversation. Journal of Pragmatics 11: 777-791.

Selting, Margret, 1988. Intonation as a contextualization device. Case studies on the role of prosody, especially intonation, in contextualizing story telling in conversation. Manuscript. To appear in: Peter Auer and Aldo di Luzio, eds., 1991. Contextualization of language. Amsterdam: Benjamins. 
Selting, Margret, 1991. Prosody as an activity-type distinctive cue in conversation: The case of socalled 'astonished questions'. Paper read at the 13. Jahrestagung der Deutschen Gesellschaft für Sprachwissenschaft, Aachen, Febr. 27th-March 1st, 1991

Tannen, Deborah, 1984. Conversational style. Norwood, NJ: Ablex.

Uhmann, Susanne, 1988. Akzenttöne, Grenztöne und Fokussilben. Zum Aufbau eines phonologischen Intonationssystems für das Deutsche. In: Hans Altmann, ed., 1988, 65-88.

Wunderlich, Dieter, 1988. Der Ton macht die Melodie - Zur Phonologie der Intonation des Deutschen. In: Hans Altmann, ed., 1988, 1-40. 